\title{
Adolescent idiopathic scoliosis: risk factors for complications and the effect of hospital volume on outcomes
}

\author{
Richard P. Menger, MD, MPA, ${ }^{1}$ Piyush Kalakoti, MD, ${ }^{1}$ Andrew J. Pugely, MD, ${ }^{2}$ \\ Anil Nanda, MD, MPH, ${ }^{1}$ and Anthony Sin, MD ${ }^{1,3}$ \\ 1Department of Neurosurgery, Louisiana State University Health Sciences Center-Shreveport; ${ }^{3}$ Shriners Hospitals for Children, \\ Shreveport, Louisiana; and ${ }^{2}$ Spine Surgery, Department of Orthopedics and Rehabilitation, University of lowa Hospitals and \\ Clinics, lowa City, lowa
}

OBJECTIVE Adolescent idiopathic scoliosis (AIS) is the most common form of scoliosis. Limited literature exists defining risk factors associated with outcomes during initial hospitalization in these patients. In this study, the authors investigated patient demographics, clinical and hospital characteristics impacting short-term outcomes, and costs in adolescent patients undergoing surgical deformity correction for idiopathic scoliosis. Additionally, the authors elucidate the impact of hospital surgical volume on outcomes for these patients.

METHODS Using the National Inpatient Sample database and appropriate International Classification of Diseases, 9th Revision codes, the authors identified adolescent patients (10-19 years of age) undergoing surgical deformity correction for idiopathic scoliosis during 2001-2014. For national estimates, appropriate weights provided by the Agency of Healthcare Research and Quality were used. Multivariable regression techniques were employed to assess the association of risk factors with discharge disposition, postsurgical neurological complications, length of hospital stay, and hospitalization costs.

RESULTS Overall, 75,106 adolescent patients underwent surgical deformity correction. The rates of postsurgical complications were estimated at $0.9 \%$ for neurological issues, $2.8 \%$ for respiratory complications, $0.8 \%$ for cardiac complications, $0.4 \%$ for infections, $2.7 \%$ for gastrointestinal complications, $0.1 \%$ for venous thromboembolic events, and $0.1 \%$ for acute renal failure. Overall, patients stayed at the hospital for an average of 5.72 days (median 5 days) and on average incurred hospitalization costs estimated at $\$ 54,997$ (median $\$ 47,909$ ). As compared with patients at low-volume centers ( $\leq 50$ operations/year), those undergoing surgical deformity correction at high-volume centers ( $>50 /$ year) had a significantly lower likelihood of an unfavorable discharge (discharge to rehabilitation) (OR 1.16, 95\% Cl 1.03-1.30, $p=0.016$ ) and incurred lower costs (mean $\$ 33,462$ vs $\$ 56,436, p<0.001$ ) but had a longer duration of stay (mean 6 vs 5.65 days, $p=0.002$ ). In terms of neurological complications, no significant differences in the odds ratios were noted between highand low-volume centers (OR 1.23, 95\% $\mathrm{Cl} 0.97-1.55, \mathrm{p}=0.091)$.

CONCLUSIONS This study provides insight into the clinical characteristics of AIS patients and their postoperative outcomes following deformity correction as they relate to hospital volume. It provides information regarding independent risk factors for unfavorable discharge and neurological complications following surgery for AIS. The proposed estimates could be used as an adjunct to clinical judgment in presurgical planning, risk stratification, and cost containment.

https://thejns.org/doi/abs/10.3171/2017.6.FOCUS17300

KEY WORDS adolescent idiopathic scoliosis; complications; cost; outcomes; hospital volume; NIS

ABBREVIATIONS AHRQ = Agency for Healthcare Research and Quality; AIS = adolescent idiopathic scoliosis; $\mathrm{CCI}=\mathrm{Charlson}$ Comorbidity Index; GEE = generalized estimating equation; HCUP = Healthcare Cost Utilization Project; HVC = high-volume center; ICD-9-CM = International Classification of Diseases, 9th Revision, Clinical Modification; LOS = length of hospital stay; LVC = low-volume center; NIS = National Inpatient Sample; NPR = number of inpatient procedures; OLS = ordinary least squares; SRS = Scoliosis Research Society.

SUBMITTED June 1, 2017. ACCEPTED June 28, 2017

INCLUDE WHEN CITING DOI: 10.3171/2017.6.FOCUS17300. 
A DOLESCENT idiopathic scoliosis (AIS) is the most common form of scoliosis, accounting for $80 \%-$ $90 \%$ of cases. It has been estimated to affect up to 4 of 100 adolescents, generally between the ages of 10 and 19 years. ${ }^{34,48}$ Genetic screening tests, the Risser grading system, and advanced imaging have helped focus operative selection. Observation is generally entertained for patients with curves less than $45^{\circ}$ and completed growth or $25^{\circ}-30^{\circ}$ with continued growth potential. The Bracing in Adolescents with Idiopathic Scoliosis Trial (BRAIST) study showed tremendous success for bracing in the prevention of curve progression to the operative threshold of $50^{\circ}$ in the skeletally mature patient. ${ }^{56}$ Surgical treatment is generally undertaken for those patients who are still growing and have a curve greater than $45^{\circ} .{ }^{48}$ In AIS patients with curves that exceed $50^{\circ}$, the curve tends to increase during adulthood at a rate of $0.5^{\circ}-2^{\circ}$ per year. ${ }^{48}$

Surgical deformity correction is generally considered safe and effective in properly selected cohorts, but it is not without risk. ${ }^{14,18,57}$ Subjective reviews on the topic place the rate of complications from $0 \%$ to $89 \% .{ }^{57}$ Data available through the Scoliosis Research Society (SRS) for 6334 patients undergoing an instrumented procedure for AIS from 2001 through 2003 show a complication rate of $5.7 \%$. Two deaths occurred. The complication rates for anterior and posterior procedures were $5.2 \%$ and $5.1 \%$, respectively; the complication rate for combined procedures was $10.2 \%$, which represented a statistically significant increase in comparison with anterior or posterior procedures. ${ }^{14}$ Specific neurological complication rates for anterior, posterior, and combined procedures were $0.26 \%$, $0.32 \%$, and $1.75 \%$, respectively. ${ }^{14}$

Studies through the SRS represent data from leading surgeons, submitted for peer review and collection. Review articles are limited by data already collected. The literature is limited on the assessment of medical risk factors associated with surgical outcomes in adolescent patients undergoing surgical correction for scoliosis following initial hospitalization. Assessment is modeled on single-institution data and subject to inherent selection bias. Analysis of factors associated with outcomes in initial hospitalization is critical to the delivery of pediatric spinal care.

To our knowledge, a comprehensive analysis has not previously been performed of the modifiable and nonmodifiable risk factors associated with the outcomes of initial hospitalization in adolescent patients undergoing deformity correction for idiopathic scoliosis using a large administrative cohort. Further, a thorough assessment of the effect of hospital surgical volume on outcomes is needed for AIS surgery. In the present study, we seek to evaluate hospital and patient factors related to complications following instrumentation procedures for correction of AIS using the National Inpatient Sample (NIS). In addition, we investigate the impact of hospital volume on outcomes.

\section{Methods \\ Data Source}

For the current study, we used the NIS database for the years 2001 through 2014. The NIS database, formulated for the Healthcare Cost Utilization Project (HCUP) by the Agency for Healthcare Research and Quality (AHRQ), is the largest publicly available inpatient database in the United States. Unweighted, it contains 5-8 million discharge-level records per year from more than 1000 participating nonfederal hospitals across several states (https:// www.hcup-us.ahrq.gov/nisoverview.jsp). The database also contains appropriate weights that are designed by the AHRQ to represent national estimates, often used for trend and epidemiological analysis.

For the years that we studied in the present work, the NIS witnessed several modifications that include changes in its nomenclature and sampling design. Before 2012, the NIS database was known as the Nationwide Inpatient Sample and was designed to represent a $20 \%$ stratified sample of US community hospitals. This included all discharge-level data from participating centers (i.e., sampled US hospitals). Beginning in 2012, structural changes to its design were made to improve the precision of national estimates by reducing sampling error. Starting in 2012, the NIS approximates a $20 \%$ stratified sample of discharges from all US community hospitals. The clinical data in the NIS are coded using the International Classification of Diseases, 9th Revision, Clinical Modification (ICD-9$\mathrm{CM}$ ) codes into several diagnoses and procedures (https:// www.hcup-us.ahrq.gov/toolssoftware/ccs/ccs.jsp).

\section{Cohort Definition}

Data for all patients registered in the NIS with a diagnosis of idiopathic scoliosis as determined by ICD-9-CM code 737.37 were extracted. This coding definition has been used in previous NIS studies. ${ }^{35,41,53}$ To define patients undergoing surgical correction for scoliosis, the extracted cohort was filtered by matching the surgical codes (81.0$81.0 x)$ with the diagnosis. Considering the objective of the study, only adolescent age groups (10-19 years) as defined by the WHO were included in the analysis. An overview of the selection criteria is depicted in Fig. 1.

\section{Outcome Measure (end point)}

Primary outcome measures were defined based on their importance for assessment of initial hospitalization outcomes. We used discharge disposition, length of hospital stay (LOS), cost of hospitalization, and neurological complications as our primary outcome measures. Secondary outcomes were postsurgical cardiac, respiratory, and gastrointestinal complications; infections; venous thromboembolic events; and acute renal failure.

Discharge disposition was dichotomized as routine or unfavorable discharge (discharge other than to home or home health care including rehabilitation). To obtain data on cost of hospitalization, HCUP group average cost-tocharge ratios were applied to hospital charges, based on hospital accounting reports from the Centers for Medicare and Medicaid Services (https://www.hcup-us.ahrq.gov/db/ state/costtocharge.jsp). Charges reflect the amount billed by the hospital for inpatient hospitalization, albeit excluding physician fees, while cost provides an estimate of the actual incurred expenses in the production of hospital ser- 


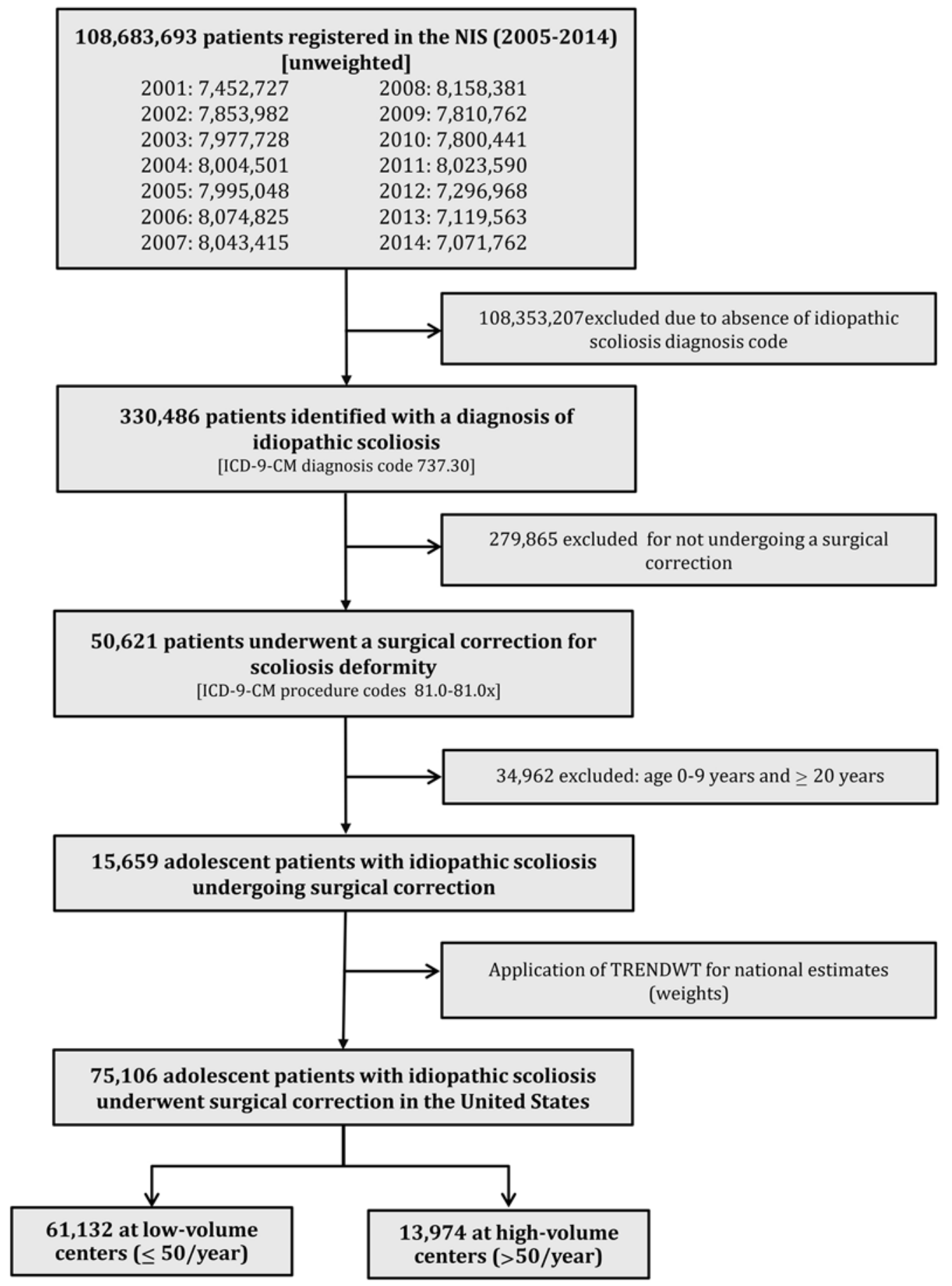

FIG. 1. Algorithm for cohort selection. TRENDWT = HCUP NIS trend weights.

vices, including wages, supplies, and utilities. With data spread over several years, we deemed it appropriate to perform inflation adjustment of individual year cost data to represent the 2017 US dollar value (https://www.bls.gov/ data/inflation_calculator.htm).

\section{Explanatory Variables}

Relevant modifiable and nonmodifiable risk factors were selected a priori and as available in the NIS database.
These included patient demographic and clinical characteristics and hospital characteristics.

Patient demographic data available in the NIS database were age (15-19 vs 10-14 years), gender, race (African American and other races with reference to "white"), primary insurance or payer (private payers, uninsured patients, and other payers with reference to publicly funded insurance such as Medicare and Medicaid), household income as determined by quartiles for patients' residential 
zip code (all income quartiles with reference to the lowest quartile).

Clinical characteristics included the following patientlevel comorbidities: seizure disorder, respiratory comorbidities (spectrum of chronic pulmonary lung disease), general metabolic conditions (morbid obesity and hypercholesterolemia), common blood disorders (anemia and coagulopathy), peripheral vascular diseases, spine-specific presentation (plegia, sensory loss, bowel/bladder dysfunction), smoking status, and alcohol use. Further, surgical correction for a scoliotic spine may vary based on disease presentation; adjustment for the total number of inpatient procedures (NPR) per patient was included. Since some of these conditions may not reflect overall medical well-being, case-mix adjustment-using the Charlson Comorbidity Index (CCI $)^{12}$ as modified by Deyo et al. ${ }^{19}$ to apply to ICD9 coding definitions-was used. ${ }^{45}$ The CCI was primarily used to mitigate unstable coefficients in regression models resulting from meager proportions for conditions such as congestive heart failure, chronic renal failure, previous history of stroke, and diabetes in the studied age group.

Hospital-level characteristics explored were hospital bedsize (medium and large with reference to small), geographical location (Midwest, South, and West, with Northeast as the reference value), and hospital surgical volume. For computing hospital surgical volume, we used the unique hospital identifier number for individual case records. The recently introduced HCUP NIS trend weights (TRENDWT) (https://www.hcup-us.ahrq. gov/db/nation/nis/trendwghts.jsp) were preferentially selected over the original discharge weights (DISCWT) to produce weighted hospital surgical estimates for scoliosis surgery due to their precision in accounting for the change in sampling design of the NIS databases for the years used in this study. Surgical volume across 1240 centers performing deformity correction for AIS was noted. Based on the average annual number of scoliosis operations performed over the study period, a hospital was labeled a high-volume center (HVC) if it performed more than 50 operations per year or a low-volume center (LVC) if the number of deformity-correction operations for AIS averaged 50 or fewer per year. Subsequently, each case record was labeled to represent the patient having undergone surgical correction for AIS at an HVC ( $\mathrm{n}=$ 14) or an $\operatorname{LVC}(n=1226)$. These volume assignments and cutoffs were selected preferentially based on dual reasoning that involved the skewed pattern of surgical volumes across centers, and by hypothesizing that roughly 1 surgery per week would qualify a center as one where AIS surgery was performed on a routine basis.

\section{Statistical Analysis}

All statistical analyses are modeled using trend weights (TRENDWT) to provide an overview of national estimates of AIS across nonfederal hospitals in the United States for 2001-2014. To derive differences in statistical significance across proportions for patients treated at centers with a defined surgical caseload, the Pearson chi-square test was employed, while an independent-samples t-test or the Wilcoxon rank-sum test was used as appropriate for quantitative values.
To examine the association of explanatory variables with primary outcome measures, we relied on multivariable regression techniques while controlling for all explanatory variables as described above. Considering the nature of the database, log-binomial models (discharge disposition and neurological complications) were fitted with generalized estimating equations (GEEs) with a sandwich variance-covariance matrix estimator. The GEE model as compared with the traditional logit model is superior in adjusting for clustering outcomes by hospitals $22,25,40,58$ and has been used in previous studies involving administrative databases. ${ }^{27,49,52}$

Metric end points (hospitalization cost and LOS) were modeled using an ordinary least squares (OLS) regression. Prior to modeling cost data, initial data exploration demonstrated a considerable degree of non-gaussian distribution. Several transformation techniques for the cost data were attempted, of which the natural logarithmic (ln) technique provided best fit to normality. Subsequently, the ln-transformed cost data were modeled using an OLS model with all previously described explanatory variables. Model assessment by regression diagnostics was performed. To ease data interpretation, the impact of risk factors on cost is being reported as a percentage change in the cost value by back-transformation. Significant values retained at alpha defined at $5 \%$ are reported.

Like the cost data, assessment of LOS demonstrated non-gaussian distribution with a remarkable degree of overdispersion associated with positive skewness. Transformation of LOS using arithmetic techniques did not provide adequate fit to normality. Therefore, it was deemed appropriate to model LOS using a log-link model with a negative binomial distribution while accounting for within-hospital correlation of outcomes. The log-link model formed the primary analysis for estimates of LOS. Like previous models, all exposures previously defined were introduced, and the impact is reported as a unit change in LOS (days).

In all models, CCI and NPR were modeled as quantitative variables, with all other variables being categorical. Prior to constructing multivariable models, we noted that, in a substantial proportion of records, values were missing for race $(21.5 \%)$, income quartiles $(2.0 \%)$, hospital bedsize $(0.3 \%)$, payer $(0.2 \%)$, and gender $(0.1 \%)$. There did not appear to be any underlying pattern. To prevent bias in the estimates resulting from missing data, the data set was iterated using a model-based multiple-imputation technique before assessment of patterns and proportions of missing values. In several epidemiological and observational cohort studies utilizing large data sets, ${ }^{7,26-28}$ multiple imputation has been credited as an effective tool for dealing with missing data compared with traditional deletion methods and single-imputation techniques..$^{30,33,46,48,50}$ In all models described above for primary outcome measures, imputed data sets were introduced, and the reported adjusted odds are results from pooled data sets.

In order to assess the impact of the defined hospital surgical volume on outcomes, sensitivity analysis was performed to control for confounding using a propensity score-adjusted traditional logit model. Matching was performed across all covariates using a nearest-neigh- 
bor algorithm with subclassification, and balance was assessed using jitter plots, histograms, and Love plots. These assessments yielded estimates that were similar to the findings of our primary analyses; therefore, they are not being reported separately. All statistical analyses were conducted using SPSS version 22.0 (IBM Corp.) and R 2.15.3 (64-bit version; R Foundation for Statistical Computing). All statistical tests were 2-tailed, with alpha set at 0.05 .

\section{Results}

\section{Patient Demographics and Hospital Characteristics}

An overview of patient demographics and clinical characteristics of patients undergoing surgical deformity correction for AIS is presented in Table 1.

Based on weighted estimates using the NIS, 75,106 adolescent patients underwent a surgical deformity correction for idiopathic scoliosis from 2001 through 2014 across nonfederal hospitals in the United States. Based on our defined cutoffs for hospital surgical volume as 50 per year (averaging 1/week), we noted that the majority of patients were operated on at LVCs $(81 \% ; n=61,132)$, while the remaining patients underwent surgical deformity correction for idiopathic scoliosis at HVCs $(19 \% ; n=13,974)$. Overall, the mean age of the cohort was $14.24 \pm 2.13$ years (median 14 years), and approximately $75 \%$ were female. Specific to adolescent age groups, a major proportion belonged to the relatively younger cohort of 10-14 years compared with the $15-19$ years group (56.5\% vs $43.5 \%$ ). Approximately two-thirds (62.3\%) of the patients were white, and approximately two-thirds (68\%) were privately insured.

Patients at HVCs were younger (mean 14.08 vs 14.28 years, $\mathrm{p}<0.001$; age group $10-14$ vs $15-19$ years, 59\% vs $56 \%, \mathrm{p}<0.001$ ), had fewer comorbidities (mean CCI 0.15 vs $0.17, p<0.001$; total number of diagnoses on record: 3.2 vs $3.57, p<0.001$ ), and on average underwent a smaller number of inpatient procedures during their hospital stay (mean 3.95 vs $4.15, \mathrm{p}<0.001$ ) compared with patients at LVCs. As for medical comorbidities, a smaller proportion of patients at HVCs had a history of seizure disorder $(2.0 \%$ vs $2.5 \%, \mathrm{p}=0.004)$, respiratory comorbidities $(8.9 \%$ vs $10.3 \%, \mathrm{p}<0.001)$, anemia $(13.6 \%$ vs $23.0 \%$, $\mathrm{p}<0.001$ ), spine-specific issues such as bowel and bladder dysfunction $(1.6 \%$ vs $2.1 \%, \mathrm{p}<0.001)$, and sensory deficit $(0.5 \%$ vs $0.9 \%, \mathrm{p}<0.001)$ compared with patients at LVCs. Likewise, the proportion of patients at HVCs with morbid obesity $(1.6 \%$ vs $2.1 \%, \mathrm{p}<0.001)$ and the proportion with a history of smoking $(0.3 \%$ vs $0.8 \%, \mathrm{p}<0.001)$ were significantly less compared with LVCs.

\section{Clinical Outcomes}

In terms of the observed clinical outcomes, we noted a case fatality rate of $0.1 \%$ following scoliosis surgery and unfavorable discharge disposition in $1.8 \%$ of cases. Overall, patients stayed at the hospital for 5.72 days (median 5 days) and on average incurred a hospitalization cost estimated at $\$ 54,997$ (median $\$ 47,909$ ). The postsurgical complication rate was estimated at $0.9 \%$ for neurological issues, $2.8 \%$ for respiratory complications, $0.8 \%$ for cardiac complications, $0.4 \%$ for infections, $2.7 \%$ for gastrointestinal complications, and $0.1 \%$ for venous thromboembolic events. Compared with patients undergoing scoliosis surgery at LVCs, patients treated at HVCs had a significantly lower proportion of unfavorable discharges $(1.1 \%$ vs $2.0 \%, p<0.001)$, gastrointestinal complications $(2.0 \%$ vs $2.9 \%, \mathrm{p}<0.001)$, venous thromboembolic events ( $\mathrm{p}<0.001)$, and renal complications $(\mathrm{p}<0.001)$; incurred lower hospitalization costs $(\$ 33,462$ vs $\$ 56,436$, $\mathrm{p}<0.001$ ); and on average stayed longer in the hospital (6 vs 5.65 days, $p=0.002$ ). No significant differences in outcomes relating to neurological complications, respiratory complications, infections, or postoperative cardiac complications were noted between patients operated on at HVCs and those operated on at LVCs. An overview of clinical outcomes across the 2 groups is depicted in Table 2. Data regarding LOS and cost are presented in Tables 3 and 4 , respectively.

\section{Derivatives From Multivariable Regression Models: Assessment of Risk Factors}

The effect of independent predictors (explanatory variables) associated with the inherent risk for an unfavorable discharge disposition is noted in Fig. 2. Independent risk factors for postoperative neurological complications are shown in Fig. 3.

We noted that patients in the age group of 15-19 years as compared with those aged 10-14 years had a relatively higher likelihood for going to rehabilitation following scoliosis surgery (OR 1.16, 95\% CI 1.03-1.30, p = 0.016) but significantly lower odds for developing a postsurgical neurological complication (OR 0.73, 95\% CI 0.61-0.88, $\mathrm{p}=0.001)$, shorter duration of hospital stay (-0.03 days, $\mathrm{p}=0.016)$, and lower total incurred costs $(-1.7 \%$ lower). General medical comorbidities and spine-specific comorbidities adversely impacted outcomes. Patients with a coagulopathy had a higher likelihood of discharge to rehabilitation, a higher LOS (+0.17 more days), and higher cost $(+17.3 \%$ higher). History of seizure disorder was likely to contribute to an unfavorable discharge (OR $1.59,95 \%$ CI $1.2-2.10, p=0.001)$, with longer LOS (+0.17 more days) and higher cost of hospitalization (+19.5\% higher) compared with cases in which there was no history of seizure. Morbidly obese patients had a longer LOS $(+0.07$ days more) and incurred higher costs (+10.2\% higher) than nonobese patients. Alcoholic patients had a greater likelihood of unfavorable discharge (OR 4.76, 95\% CI 2.56-8.84, p $<0.001$ ) and neurological complications (OR 16.59, 95\% CI 8.10-34.02, $\mathrm{p}<0.016)$. Previous paralysis, sensory loss, and bowel and bladder dysfunction were associated with unfavorable discharge and with neurological complications during the postoperative hospital stay as well as longer LOS and higher costs.

For binary end points and the log-link model for LOS, adjusted odds ratios along with $95 \%$ confidence intervals are reported, supplemented with a depiction of estimates on forest plots (Figs. 2 and 3). These models demonstrated fairly reasonable discriminatory ability with computed c-statistics or area under the curve values such as 0.87 , 0.82 , and 0.81 for discharge disposition, neurological complication, and LOS, respectively. An overview of factors 
TABLE 1. Demographic and clinical characteristics of patients undergoing surgical deformity correction for AIS in the US (2001-2014)

\begin{tabular}{|c|c|c|c|c|}
\hline Characteristic & LVCs $(n=61,132)$ & HVCs $(n=13,974)$ & Overall $(n=75,106)$ & $p$ Value \\
\hline \multicolumn{5}{|l|}{ Age in yrs } \\
\hline Mean \pm SD & $14.28 \pm 2.14$ & $14.08 \pm 2.08$ & $14.24 \pm 2.13$ & $<0.001$ \\
\hline $10-14$ & $34,115(55.8)$ & $8307(59.4)$ & $42,422(56.5)$ & $<0.001$ \\
\hline $15-19$ & $27,017(44.2)$ & $5667(40.6)$ & $32,684(43.5)$ & $<0.001$ \\
\hline Female gender, $\mathrm{n}(\%)^{*}$ & $45,761(74.9)$ & $10,211(73.1)$ & $55,972(74.6)$ & $<0.001$ \\
\hline \multicolumn{5}{|l|}{ Race, $n(\%)^{*}$} \\
\hline White & $32,440(64.8)$ & $4342(49.0)$ & $36,782(62.4)$ & $<0.001$ \\
\hline African American & $8286(16.5)$ & $1439(16.3)$ & $9725(16.5)$ & 0.493 \\
\hline Other & $9352(18.7)$ & $3072(34.7)$ & $12,424(21.1)$ & $<0.001$ \\
\hline \multicolumn{5}{|l|}{ Income, $\mathrm{n}(\%)^{*}$} \\
\hline Lowest quartile & $12,324(20.6)$ & $2391(17.5)$ & $14,715(20.0)$ & $<0.001$ \\
\hline 2nd quartile & $13,488(22.5)$ & $3058(22.3)$ & $16,546(22.5)$ & 0.657 \\
\hline 3rd quartile & $15,292(25.5)$ & $3676(26.9)$ & $18,968(25.8)$ & $<0.001$ \\
\hline 4th quartile & $18,804(31.4)$ & $4564(33.3)$ & $23,368(31.8)$ & $<0.001$ \\
\hline \multicolumn{5}{|l|}{ Primary payer, $\mathrm{n}(\%)^{*}$} \\
\hline Medicare \& Medicaid & $15,813(25.9)$ & $3502(25.1)$ & $19,315(25.8)$ & 0.037 \\
\hline Private & $41,385(67.9)$ & $9296(66.6)$ & $50,681(67.6)$ & 0.003 \\
\hline Self & $745(1.2)$ & $258(1.8)$ & $1003(1.3)$ & $<0.001$ \\
\hline Other & $3019(5.0)$ & $907(6.5)$ & $3926(5.2)$ & $<0.001$ \\
\hline \multicolumn{5}{|l|}{ Bedsize, n (\%) } \\
\hline Small & $11,468(18.8)$ & $3237(23.2)$ & $14,705(19.6)$ & $<0.001$ \\
\hline Medium & $14,039(23.0)$ & $5573(39.9)$ & $19,612(26.2)$ & $<0.001$ \\
\hline Large & $35,430(58.1)$ & $5164(37.0)$ & $40,594(54.2)$ & $<0.001$ \\
\hline \multicolumn{5}{|l|}{ Region, n (\%) } \\
\hline Northeast & $12,172(19.9$ & $1531(11.0)$ & $13,703(18.2)$ & $<0.001$ \\
\hline Midwest & $13,157(21.5)$ & $3700(26.5)$ & $16,857(22.4)$ & $<0.001$ \\
\hline South & $22,839(37.4)$ & $6740(48.2)$ & $29,579(39.4)$ & $<0.001$ \\
\hline West & $12,963(21.2)$ & $2003(14.3)$ & $14,966(19.9)$ & $<0.001$ \\
\hline \multicolumn{5}{|l|}{ Clinical characteristics, $n(\%)$} \\
\hline Seizure disorder & $1503(2.5)$ & $286(2.0)$ & $1789(2.4)$ & 0.004 \\
\hline COPD & $6306(10.3)$ & $1249(8.9)$ & 7555 (10.1) & $<0.001$ \\
\hline Hypercholesterolemia & $59(0.1)$ & $\mathrm{x}$ & $68(0.1)$ & 0.255 \\
\hline Smoking status & $493(0.8)$ & $38(0.3)$ & $531(0.7)$ & $<0.001$ \\
\hline Alcohol abuse & $20(0.0)$ & $\mathrm{X}$ & $20(0.0)$ & $0.038 \dagger$ \\
\hline Obesity & $1283(2.1)$ & $226(1.6)$ & $1509(2.0)$ & $<0.001$ \\
\hline PVD & $123(0.2)$ & $27(0.2)$ & $150(0.2)$ & 0.849 \\
\hline Coagulopathy & $1449(2.4)$ & $322(2.3)$ & $1771(2.4)$ & 0.644 \\
\hline Anemia & $14,089(23.0)$ & $1900(13.6)$ & $15,989(21.3)$ & $<0.001$ \\
\hline Paralysis & $482(0.8)$ & $129(0.9)$ & $611(0.8)$ & 0.110 \\
\hline Bowel/bladder dysfunction & $1271(2.1)$ & $229(1.6)$ & $1500(2.0)$ & 0.001 \\
\hline Sensory deficits & $562(0.9)$ & $65(0.5)$ & $627(0.8)$ & $<0.001$ \\
\hline Osteoporosis & $211(0.3)$ & $11(0.1)$ & $222(0.3)$ & $<0.001$ \\
\hline \multicolumn{5}{|l|}{ CCl score } \\
\hline Low, n (\%) & $60,929(99.7)$ & $13,911(99.5)$ & $74,840(99.6)$ & 0.033 \\
\hline Moderate/high, $\mathrm{n}(\%)$ & $203(0.3)$ & $63(0.5)$ & $266(0.4)$ & \\
\hline Mean & 0.17 & 0.15 & 0.17 & $<0.001$ \\
\hline \multicolumn{5}{|l|}{ Total no. of inpatient procedures } \\
\hline Mean & 4.15 & 3.95 & 4.11 & $<0.001$ \\
\hline Median & 4 & 4 & 4 & \\
\hline
\end{tabular}


» CONTINUED FROM PAGE 6

TABLE 1. Demographic and clinical characteristics of patients undergoing surgical deformity correction for AIS in the US (2001-2014)

\begin{tabular}{|c|c|c|c|c|}
\hline Characteristic & LVCs $(n=61,132)$ & HVCs $(n=13,974)$ & Overall $(n=75,106)$ & $p$ Value \\
\hline \multicolumn{5}{|l|}{ Total no. of diagnoses } \\
\hline Mean & 3.57 & 3.20 & 3.5 & $<0.001$ \\
\hline Median & 3 & 2 & 2 & \\
\hline
\end{tabular}

COPD = chronic obstructive pulmonary disease; $P V D=$ peripheral vascular disease.

Mean values are given with SDs. Boldface type indicates statistical significance with alpha set at 0.05 . X indicates output suppressed in compliance with HCUP reporting guidelines for cells with values $\leq 10$.

* Frequencies and proportions after exclusion of patients with missing values for gender $(0.1 \%)$, race $(21.5 \%)$, income quartiles $(2.0 \%)$, primary payer $(0.2 \%)$, and hospital bedsize $(0.3 \%)$.

$\dagger$ Based on the Fisher exact test.

$\ddagger \mathrm{CCl}$ scores of $0-2$ were considered low, and scores $\geq 3$ were considered moderate/high.

influencing LOS and hospital cost as a unit and percentage change following back-transformation of estimates is presented in Tables 3 and 4, respectively.

\section{Derivatives From Multivariable Regression Models: Impact of Volume on Outcomes}

As compared with patients at LVCs, those undergoing surgical deformity correction at HVCs had a significantly lower likelihood of an unfavorable discharge (OR 1.16, 95\% CI 1.03-1.30, $\mathrm{p}=0.016)$ and incurred lower costs $(-12.6 \%$ lower, $\mathrm{p}<0.001)$ but had relatively longer LOS (+0.09 more days). In terms of neurological complications, no significant differences in the odds ratios were noted across HVCs and LVCs (OR 1.23, 95\% CI 0.97-1.55, p = 0.091).

\section{Discussion}

Our study provides insight into the clinical characteristics of AIS patients (Table 1) and their postoperative outcomes following deformity correction (Table 2) in relationship to hospital volume. It provides information regarding LOS (Table 3) and cost (Table 4) and independent risk factors for unfavorable discharge (Fig. 2) and neurological complications (Fig. 3) following surgery for AIS.

Selection of AIS patients for surgery is pertinent for optimizing outcomes, and it is often based on spinal curvature and the potential for future growth. Medical comorbidities or modifiable risk factors might plausibly be expected to impact outcomes, and identification of these critical modifiable factors is of paramount importance for patient well-being, optimization of outcomes, and reduc-

TABLE 2. Postoperative outcomes in patients undergoing surgical deformity correction for AIS in the US (2001-2014)

\begin{tabular}{|c|c|c|c|c|}
\hline Variable & LVCs $(n=61,132)$ & HVCs $(n=13,974)$ & Overall $(n=75,106)$ & $\mathrm{p}$ Value \\
\hline Inpatient mortality, $\mathrm{n}(\%)^{*}$ & $51(0.1)$ & $18(0.1)$ & $69(0.1)$ & 0.110 \\
\hline Unfavorable discharge, $\mathrm{n}(\%)^{*} \dagger$ & $1204(2.0)$ & $154(1.1)$ & $1358(1.8)$ & $<0.001$ \\
\hline \multicolumn{5}{|l|}{ LOS, days } \\
\hline Mean & 5.65 & 6.00 & 5.72 & 0.002 \\
\hline Median & 5 & 5 & 5 & \\
\hline \multicolumn{5}{|l|}{ Hospital cost, US\$† } \\
\hline Mean & 56,436 & 33,462 & 54,997 & $<0.001$ \\
\hline Median & 48,920 & 43,447 & 47,909 & \\
\hline IQR & $33,056-64,784$ & $30,443-56,450$ & $32,502-63,316$ & \\
\hline Neurological complications, $\mathrm{n}(\%)$ & $519(0.8)$ & $129(0.9)$ & $648(0.9)$ & 0.392 \\
\hline Respiratory complications, n (\%) & $1658(2.7)$ & $410(2.9)$ & $2068(2.8)$ & 0.148 \\
\hline Cardiac complications, n (\%) & $838(0.8)$ & $172(0.7)$ & $1010(0.8)$ & 0.265 \\
\hline Wound infections, n (\%) & $404(0.4)$ & $92(0.4)$ & $496(0.4)$ & 0.923 \\
\hline GI complications, n (\%) & $1770(2.9)$ & $284(2.0)$ & $2054(2.7)$ & $<0.001$ \\
\hline VTE, n (\%) & $68(0.1)$ & $X$ & $73(0.1)$ & $<0.001 \S$ \\
\hline ARF, n (\%) & $98(0.2)$ & $x$ & $102(0.1)$ & $<0.001 \S$ \\
\hline
\end{tabular}

$\mathrm{ARF}=$ acute renal failure; $\mathrm{GI}$ = gastrointestinal; $I \mathrm{IQ}=$ interquartile range; VTE = venous thromboembolism.

Boldface type indicates statistical significance with alpha set at 0.05 . X indicates output suppressed in compliance with HCUP reporting guidelines for cells with values $\leq 10$.

* Values based on exclusion of missing patients for inpatient mortality $(0.005 \%)$ and unfavorable discharge $(0.002 \%)$.

$\dagger$ Patients who died during their hospitalization (inpatient mortality) were excluded.

$\ddagger$ Inflation-adjusted values over the 10-year-period (adjusted to 2013 US\$ amounts using the National Consumer Price Index calculator).

$\S$ Based on the Fisher exact test. 
TABLE 3. Association of factors associated with LOS for adolescent patients undergoing surgical deformity correction for AIS

\begin{tabular}{|c|c|c|c|}
\hline \multirow[b]{2}{*}{ Factor } & \multicolumn{2}{|c|}{ Unit (day) Change in LOS } & \multirow[b]{2}{*}{$\begin{array}{c}p \\
\text { Value }\end{array}$} \\
\hline & $\begin{array}{c}\text { Unit } \\
\text { Change }\end{array}$ & $95 \% \mathrm{Cl}$ & \\
\hline \multicolumn{4}{|l|}{ Factors associated $w / \uparrow$ cost } \\
\hline Other race* & +0.02 & $0.00-0.03$ & 0.033 \\
\hline 2nd income quartile $\dagger$ & +0.02 & $0.01-0.03$ & $<0.001$ \\
\hline 3rd income quartile $†$ & +0.03 & $0.02-0.05$ & $<0.001$ \\
\hline Highest income quartile† & +0.06 & $0.05-0.08$ & $<0.001$ \\
\hline West region $\ddagger$ & +0.03 & $0.01-0.04$ & $<0.001$ \\
\hline No. of procedures & +0.06 & $0.05-0.08$ & $<0.001$ \\
\hline Obesity & +0.07 & $0.04-0.10$ & $<0.001$ \\
\hline Paralysis & +0.10 & $0.01-0.17$ & 0.034 \\
\hline Sensory loss & +0.11 & $0.06-0.17$ & $<0.001$ \\
\hline Coagulopathy & +0.17 & $0.13-0.19$ & $<0.001$ \\
\hline Seizure disorder & +0.17 & $0.14-0.21$ & $<0.001$ \\
\hline Bowel/bladder dysfunction & +0.17 & $0.13-0.21$ & $<0.001$ \\
\hline PVD & +0.22 & $0.20-0.25$ & $<0.001$ \\
\hline $\mathrm{CCl}$ score & +0.39 & $0.22-0.57$ & $<0.001$ \\
\hline HVC (>50/yr)§ & +0.09 & $0.08-0.10$ & $<0.001$ \\
\hline \multicolumn{4}{|l|}{ Factors associated w/ $\downarrow$ cost } \\
\hline South region $\ddagger$ & -0.08 & -0.09 to -0.07 & $<0.001$ \\
\hline Private insurance incl HMO & -0.07 & -0.08 to -0.06 & $<0.001$ \\
\hline Other payers $\rrbracket$ & -0.03 & -0.05 to -0.01 & 0.012 \\
\hline Medium bedsize ${ }^{* *}$ & -0.06 & -0.07 to -0.05 & $<0.001$ \\
\hline Age group 15-19 yrst† & -0.03 & -0.04 to -0.02 & $<0.001$ \\
\hline Female gender & -0.03 & -0.04 to -0.02 & $<0.001$ \\
\hline Large bedsize ${ }^{* *}$ & -0.03 & -0.04 to -0.02 & $<0.001$ \\
\hline
\end{tabular}

$\mathrm{HMO}=$ health maintenance organization; incl = including; $\uparrow=$ increased; $\downarrow=$ decreased.

Boldface type indicates statistical significance with alpha set at 0.05 .

* In comparison with white race.

† In comparison with lowest income quartile.

$\ddagger$ In comparison with Northeast region hospitals.

$\S$ In comparison with LVCs ( $\leq 50 /$ year).

If In comparison with uninsured patients.

** In comparison with small-bedsize hospital.

†† In comparison with patients aged 10-14 years.

tion of costs. In the backdrop of the seismic changes in the US health care system and the focus on cost containment and outcome monitoring, identification of risk factors for suboptimal outcomes is critical.

\section{Improving Clinical Outcomes: Impact of Volume on Outcomes}

Our data largely support the notion that fusion surgery for AIS is generally safe and effective. Data from 14 years and more than 75,000 adolescent patients who underwent surgical deformity correction showed an overall neurological complication rate of $0.9 \%$. The specific postsurgical complication rates were estimated at $2.8 \%$ for respiratory complications, $0.8 \%$ for cardiac complications, $0.4 \%$ for infections, $2.7 \%$ for gastrointestinal complications, and
TABLE 4. Association of factors associated with hospitalization costs for adolescent patients undergoing surgical deformity correction for AIS

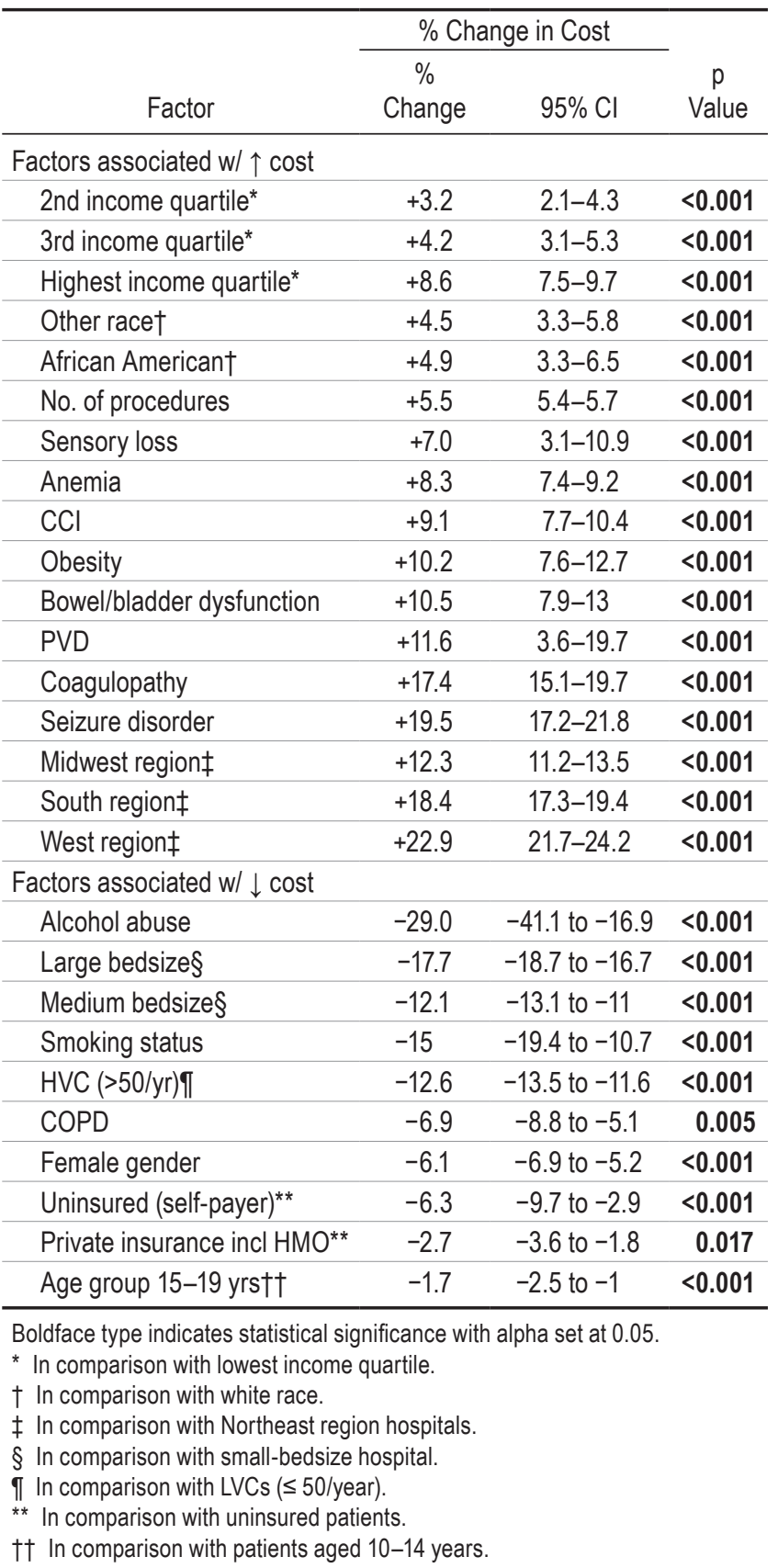

$0.1 \%$ for venous thromboembolic events. This is in line with previously published data.

AIS surgery has previously been associated with postoperative improvements in SRS measures for pain, general self-image, function, and level of activity. ${ }^{38}$ Dede et al. noted freehand screw placement as safe and reliable, with only 8 malpositioned screws among 5923 patients $(0.14 \%){ }^{18}$ However, the focus should largely be on multidisciplinary care. For example, multidisciplinary perioperative care can reduce surgical site infections, help prevent neurological injury, and reduce surgical blood loss. ${ }^{11}$ 


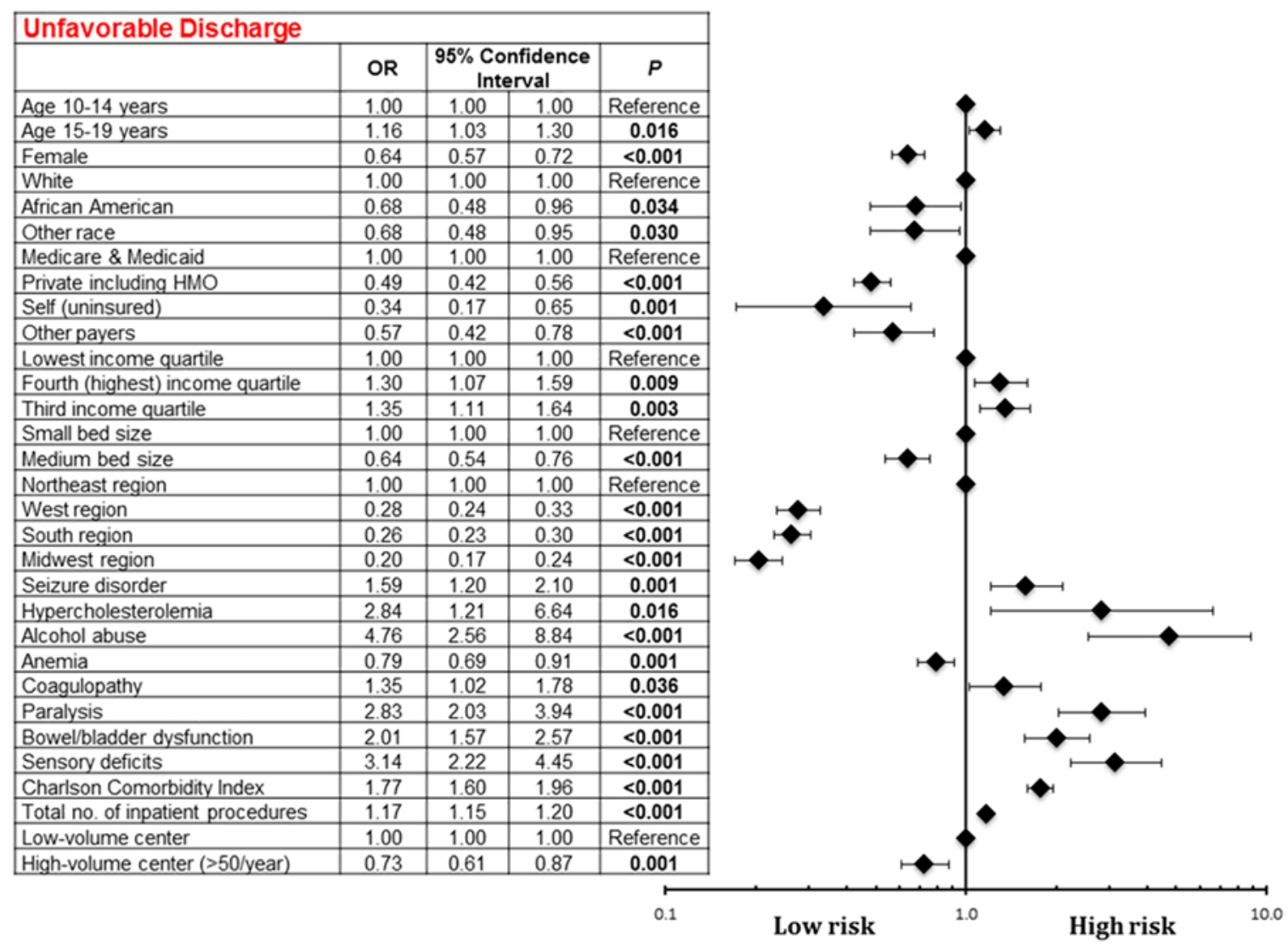

FIG. 2. Multivariable regression depicting factors associated with unfavorable discharge in adolescent patients undergoing surgical deformity correction for idiopathic scoliosis. HMO = health maintenance organization.

This is reinforced by the repetitive nature of high hospital volume in our report. Our data do not show a statistically significant difference between HVCs and LVCs with respect to rates of neurological complications. However, the data do show a lower likelihood of unfavorable discharge and lower incurred cost $(\$ 33,462$ vs $\$ 56,436)$ despite a relatively longer LOS (6 vs 5.65 days). This speaks to a systems-based approach. For example, surgical site infections are seen in $0.5 \%-6.7 \%$ of patients undergoing pediatric deformity surgery. ${ }^{11,32}$ Institutional standardized protocols can reduce the relative risk of infections by $50 \% .^{1,11}$ This is a volume-reinforced pattern involving multiple personnel and including such varied components as preadmission bathing, nutrition control, prophylactic antibiotic dosing, operating room traffic, and postoperative wound management. ${ }^{11}$ Vitale et al. recommend a 14-point best-practice guideline for reducing infections for high-risk pediatric spinal surgery. ${ }^{55}$ This is a systemsbased approach related to volume and repetition.

Previous studies have explored the volume-outcome relationship in the context of several neurosurgical procedures, ${ }^{2-6,15,16,23,24,26,28,29,44,51,54}$ including those involving the spine. ${ }^{17,20,28,42,43}$ For scoliosis surgery, Patil et al ${ }^{41}$ defined 5 hospital surgical volume cutoffs ranging from $<21$ operations per year to $>147$ per year. Further, the authors investigated in-hospital mortality, discharge disposition, and complications following surgical correction. Our data resonate with those of Patil et al., with a more streamlined approach specific to AIS combined with robust analysis and convenient hospital surgical volume definitions. In the current health care scenario, distinguishing outcomes across centers with variable surgical volume, especially for complex instrumentation such as that required for correcting AIS, is pertinent for benchmarking outcomes, assessing total quality, and strengthening referral systems. In several centers, a limited number of specialized surgeons serves as a proxy for better outcomes for the provider facility. With improved outcomes at HVCs, it is evident that the surgeon represents the leadership within a systemsbased platform for reducing complications and maximizing outcomes.

\section{Improving Clinical Outcomes: Cohort Selection}

Our series noted that spine-specific neurological symptomatology can adversely impact outcomes and lead to unfavorable discharge. Preoperatively, patients with paralysis and those with loss of bowel or bladder control or sensory loss who undergo instrumentation for a scoliotic spine have an increased disposition for postdischarge rehabilitation, increased LOS, and increased costs for hospitalization. Likewise, estimates for several other medical comorbidities were quantified in the current study to provide an overview of the impact of these nonmodifiable factors on outcomes. Preoperative correction of anemia or coagulopathy can help avert postsurgical complications 


\begin{tabular}{|l|c|c|c|c|}
\hline Neurological Complications & OR & $\begin{array}{c}\text { 95\% Confidence } \\
\text { Interval }\end{array}$ & $P$ \\
\hline Age 10-14 years & 1.00 & 1.00 & 1.00 & Reference \\
\hline Age 15-19 years & 0.73 & 0.61 & 0.88 & $\mathbf{0 . 0 0 1}$ \\
\hline Lowest income quartile & 1.00 & 1.00 & 1.00 & Reference \\
\hline Second income quartile & 0.73 & 0.53 & 0.99 & $\mathbf{0 . 0 4 5}$ \\
\hline Small bed size & 1.00 & 1.00 & 1.00 & Reference \\
\hline Medium bed size & 1.52 & 1.17 & 1.99 & $\mathbf{0 . 0 0 2}$ \\
\hline Northeast region & 1.00 & 1.00 & 1.00 & Reference \\
\hline South region & 0.54 & 0.42 & 0.70 & $<0.001$ \\
\hline Midwest region & 0.58 & 0.44 & 0.76 & $<0.001$ \\
\hline Seizure disorder & 0.27 & 0.18 & 0.41 & $<0.001$ \\
\hline COPD & 0.25 & 0.10 & 0.60 & $\mathbf{0 . 0 0 2}$ \\
\hline Smoking & 0.31 & 0.16 & 0.59 & $<0.001$ \\
\hline Alcohol abuse & 16.59 & 8.10 & 34.02 & $<0.001$ \\
\hline Sensory deficits & 7.23 & 5.24 & 9.98 & $<0.001$ \\
\hline Total no. of inpatient procedures & 1.18 & 1.14 & 1.21 & $<0.001$ \\
\hline Charlson Comorbidity Index & 4.44 & 3.25 & 6.07 & $<0.001$ \\
\hline Low-volume center & 1.00 & 1.00 & 1.00 & Reference \\
\hline High-volume center (>50/year) & 1.23 & 0.97 & 1.55 & 0.091 \\
\hline
\end{tabular}

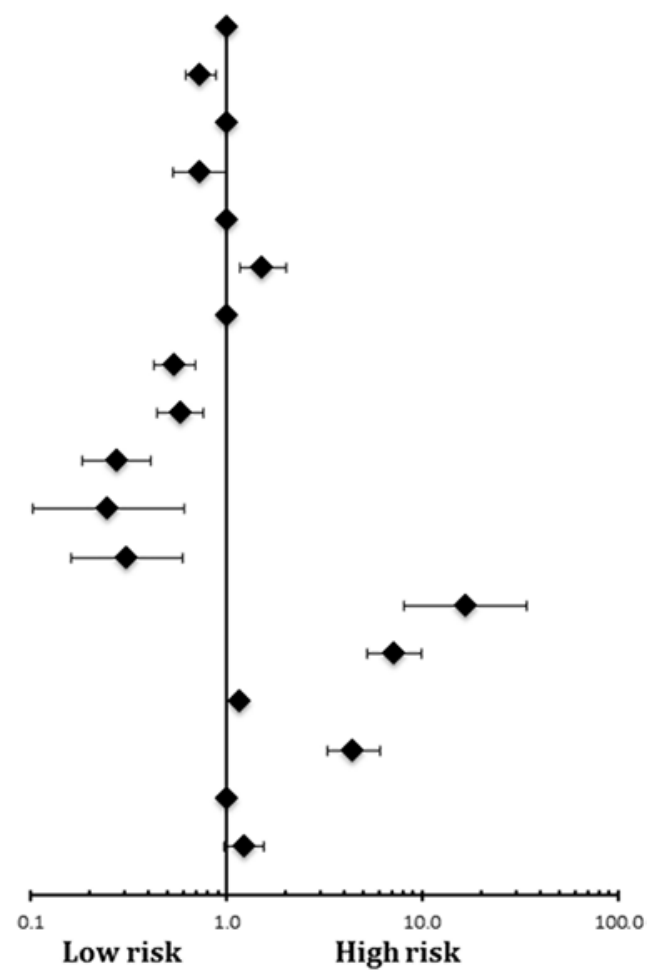

FIG. 3. Multivariable regression depicting factors associated with the development of postoperative neurological complications in adolescent patients undergoing deformity correction for idiopathic scoliosis. COPD = chronic obstructive pulmonary disease.

and improve discharge disposition. This largely mirrors findings reported in the literature on adults wherein major complications for patients can be related to age, medical comorbidities, and the significance of surgical correction. ${ }^{13}$ Historically, factors are well defined regarding the minimum clinically important difference for patients' appearance outcome after AIS deformity surgery as related to preoperative appearance scores, body weight, and correction of the thoracic and lumbar Cobb angles. ${ }^{8}$ Our data in conjunction with this information can aid in shared decision making with patients and their families.

\section{Cost Containment and Future Investigation}

Cost containment will be a leading factor in upcoming health care reform for both public and private payers. The Congressional Budget Office notes that if the health care laws remain generally unchanged, public debt will exceed the gross domestic product in 2040. With the advent of the Affordable Care Act and increasing Medicaid coverage, a subset of the pediatric population could see significant managed care hurdles to the implementation and preauthorization of spinal deformity procedures..$^{36,38}$ Hence, our data provide an important introduction at a national data level to factors that may alter the cost of care delivery.

In a recent analysis, Martin et al. evaluated utilization rates and hospital charges for AIS patients who under- went fusion surgery between 2001 and 2011. ${ }^{35}$ Based on their analysis, the authors depicted an overall trend of substantially increasing hospital charges against a relatively constant rate of surgical utilization. The popularity of pedicle screw-based constructs and innovations in spinal instrumentation has been attributed to the rising charges.

Overall, patients represented by our data stayed at the hospital for an average of 5.72 days (median 5 days) and on average incurred a hospitalization cost estimated at $\$ 54,997$ (median $\$ 47,909$ ). Our data begin to shed light on some of the independent predictive and preventive factors relating to hospital cost. Potential drivers influencing the cost of hospitalization included African American race, higher income quartiles, higher number of inpatient procedures, morbid obesity, anemia, coagulopathy, and neurological symptoms such as epilepsy and sensory and preoperative motor deficits. Meanwhile, larger hospitals, higher volume, and older patient age drove costs down.

\section{Limitations}

Data obtained from the NIS, a family of the HCUP data set, pose several limitations that are well known to arise from the use of administrative databases or registries. ${ }^{21,31}$

First, the clinical characteristics coded in the NIS for individual records are based on ICD-9-CM coding defi- 
nitions. Although individual facilities employ certified medical coders for billing purposes, the possibility of the analyzed discharge records being subject to errors in coding and omissions cannot be ruled out. ${ }^{9,39}$ Second, the use of ICD-9-CM codes themselves introduces some bias due to their broad-based nature for defining conditions or procedures. The procedure codes used to identify patients undergoing surgical correction of spinal scoliosis do not provide specifics on the type of instrumentation or implants. Furthermore, residual confounding may have influenced some of the observed estimates.

Failure to assess critical intraoperative parameters, such as duration of surgery and volume of blood loss; radiological findings, such as scoliosis grade and Cobb angle measurement; or skeletal maturity is likely to impact outcomes. Information about these variables is not available in the data set. Further, the NIS lacks longitudinal data, including follow-up, outpatient visits, and readmission data, thereby restricting the present analysis to single admissions only. Also, the assessment of facility surgical volume could not account for individual surgeons' volumes. Surrogates for volume are available at the hospital structure, but per the database configuration, data on individual surgeons' volumes are not available.

Despite these limitations, which require careful and appropriate application of the data, the database has been used in the literature ${ }^{10}$ and shown to have both internal and external validity. The NIS is the largest inpatient all-payer database assembled in the United States; as such it provides the best baseline estimates for future research and more granular studies.

\section{Conclusions}

Using a large administrative cohort and robust statistical techniques, we quantified several risk factors associated with discharge disposition, postoperative neurological complication, LOS, and hospitalization cost for adolescent patients with idiopathic spinal scoliosis. The proposed estimates could be used as an adjunct to clinical judgment in presurgical planning and risk stratification and to aid in patient counseling and shared decision making. The derived estimates for factors impacting hospital stay and costs may serve to guide policy makers in evaluating reimbursement strategies for sicker patients. Further, these estimates can potentially be used for in-hospital auditing of outcomes and costs and form an essential part of the cost-containment debate.

\section{References}

1. Ballard MR, Miller NH, Nyquist AC, Elise B, Baulesh DM, Erickson MA: A multidisciplinary approach improves infection rates in pediatric spine surgery. J Pediatr Orthop 32:266-270, 2012

2. Bardach NS, Zhao S, Gress DR, Lawton MT, Johnston SC: Association between subarachnoid hemorrhage outcomes and number of cases treated at California hospitals. Stroke 33:1851-1856, 2002

3. Barker FG II: Craniotomy for the resection of metastatic brain tumors in the U.S., 1988-2000: decreasing mortality and the effect of provider caseload. Cancer 100:999-1007, 2004

4. Barker FG II, Amin-Hanjani S, Butler WE, Ogilvy CS,
Carter BS: In-hospital mortality and morbidity after surgical treatment of unruptured intracranial aneurysms in the United States, 1996-2000: the effect of hospital and surgeon volume. Neurosurgery 52:995-1009, 2003

5. Barker FG II, Carter BS, Ojemann RG, Jyung RW, Poe DS, McKenna MJ: Surgical excision of acoustic neuroma: patient outcome and provider caseload. Laryngoscope 113:13321343,2003

6. Barker FG II, Curry WT Jr, Carter BS: Surgery for primary supratentorial brain tumors in the United States, 1988 to 2000: the effect of provider caseload and centralization of care. Neuro Oncol 7:49-63, 2005

7. Bekelis K, Missios S, Mackenzie TA: Prehospital helicopter transport and survival of patients with traumatic brain injury. Ann Surg 261:579-585, 2015

8. Bennett JT, Samdani AF, Bastrom TP, Ames RJ, Miyanji F, Pahys JM, et al: Factors affecting the outcome in appearance of AIS surgery in terms of the minimal clinically important difference. Eur Spine J 26:1782-1788, 2017

9. Berthelsen CL: Evaluation of coding data quality of the HCUP National Inpatient Sample. Top Health Inf Manage 21:10-23, 2000

10. Bohl DD, Basques BA, Golinvaux NS, Baumgaertner MR, Grauer JN: Nationwide Inpatient Sample and National Surgical Quality Improvement Program give different results in hip fracture studies. Clin Orthop Relat Res 472:1672-1680, 2014

11. Borden TC, Bellaire LL, Fletcher ND: Improving perioperative care for adolescent idiopathic scoliosis patients: the impact of a multidisciplinary care approach. J Multidiscip Healthc 9:435-445, 2016

12. Charlson ME, Pompei P, Ales KL, MacKenzie CR: A new method of classifying prognostic comorbidity in longitudinal studies: development and validation. J Chronic Dis 40:373383, 1987

13. Cho SK, Bridwell KH, Lenke LG, Yi JS, Pahys JM, Zebala LP, et al: Major complications in revision adult deformity surgery: risk factors and clinical outcomes with 2- to 7-year follow-up. Spine (Phila Pa 1976) 37:489-500, 2012

14. Coe JD, Arlet V, Donaldson W, Berven S, Hanson DS, Mudiyam R, et al: Complications in spinal fusion for adolescent idiopathic scoliosis in the new millennium. A report of the Scoliosis Research Society Morbidity and Mortality Committee. Spine (Phila Pa 1976) 31:345-349, 2006

15. Cross DT III, Tirschwell DL, Clark MA, Tuden D, Derdeyn $\mathrm{CP}$, Moran CJ, et al: Mortality rates after subarachnoid hemorrhage: variations according to hospital case volume in 18 states. J Neurosurg 99:810-817, 2003

16. Curry WT, McDermott MW, Carter BS, Barker FG II: Craniotomy for meningioma in the United States between 1988 and 2000: decreasing rate of mortality and the effect of provider caseload. J Neurosurg 102:977-986, 2005

17. Dasenbrock HH, Clarke MJ, Witham TF, Sciubba DM, Gokaslan ZL, Bydon A: The impact of provider volume on the outcomes after surgery for lumbar spinal stenosis. Neurosurgery 70:1346-1354, 2012

18. Dede O, Ward WT, Bosch P, Bowles AJ, Roach JW: Using the freehand pedicle screw placement technique in adolescent idiopathic scoliosis surgery: what is the incidence of neurological symptoms secondary to misplaced screws? Spine (Phila Pa 1976) 39:286-290, 2014

19. Deyo RA, Cherkin DC, Ciol MA: Adapting a clinical comorbidity index for use with ICD-9-CM administrative databases. J Clin Epidemiol 45:613-619, 1992

20. Farjoodi P, Skolasky RL, Riley LH: The effects of hospital and surgeon volume on postoperative complications after lumbar spine surgery. Spine (Phila Pa 1976) 36:2069-2075, 2011

21. Gologorsky Y, Knightly JJ, Lu Y, Chi JH, Groff MW: Im- 
proving discharge data fidelity for use in large administrative databases. Neurosurg Focus 36(6):E2, 2014

22. Harrell FE Jr: Regression Modeling Strategies: With Applications to Linear Models, Logistic Regression, and Survival Analysis. New York: Springer, 2001

23. Hoh BL, Rabinov JD, Pryor JC, Carter BS, Barker FG II: Inhospital morbidity and mortality after endovascular treatment of unruptured intracranial aneurysms in the United States, 1996-2000: effect of hospital and physician volume. AJNR Am J Neuroradiol 24:1409-1420, 2003

24. Holt PJ, Poloniecki JD, Loftus IM, Thompson MM: The relationship between hospital case volume and outcome from carotid endartectomy in England from 2000 to 2005. Eur J Vasc Endovasc Surg 34:646-654, 2007

25. Huber PJ: The behavior of maximum likelihood estimates under nonstandard conditions, in Proceedings of the Fifth Berkeley Symposium on Mathematics and Probability. Berkeley, CA: University of California Press, 1967, Vol 1, pp 221-233

26. Kalakoti P, Ahmed O, Bollam P, Missios S, Wilden J, Nanda A: Predictors of unfavorable outcomes following deep brain stimulation for movement disorders and the effect of hospital case volume on outcomes: an analysis of 33,642 patients across 234 US hospitals using the National (Nationwide) Inpatient Sample from 2002 to 2011. Neurosurg Focus 38(6):E4, 2015

27. Kalakoti P, Missios S, Kukreja S, Storey C, Sun H, Nanda A: Impact of associated injuries in conjunction with fracture of the axis vertebra on inpatient outcomes and postoperative complications: a Nationwide Inpatient Sample analysis from 2002 to 2011. Spine J 16:491-503, 2016

28. Kalakoti P, Missios S, Menger R, Kukreja S, Konar S, Nanda A: Association of risk factors with unfavorable outcomes following resection of adult benign intradural spine tumors and the effect of hospital volume on outcomes: an analysis of 18,297 patients across 774 US hospitals using the National Inpatient Sample 2002-2011. Neurosurg Focus 39(2):E4, 2015

29. Kalkanis SN, Eskandar EN, Carter BS, Barker FG II: Microvascular decompression surgery in the United States, 1996 to 2000: mortality rates, morbidity rates, and the effects of hospital and surgeon volumes. Neurosurgery 52:1251-1262, 2003

30. Klebanoff MA, Cole SR: Use of multiple imputation in the epidemiologic literature. Am J Epidemiol 168:355-357, 2008

31. Lawthers AG, McCarthy EP, Davis RB, Peterson LE, Palmer RH, Iezzoni LI: Identification of in-hospital complications from claims data. Is it valid? Med Care 38:785-795, 2000

32. Li Y, Glotzbecker M, Hedequist D: Surgical site infection after pediatric spinal deformity surgery. Curr Rev Musculoskelet Med 5:111-19, 2012

33. Little RJA, Rubin DB: Statistical Analysis with Missing Data, ed 2. Hoboken, NJ: Wiley, 2002

34. Lonstein J: Idiopathic scoliosis, in Lonstein JE, Winter RB, Bradford DS, et al (eds): Moe's Textbook of Scoliosis and Other Spinal Deformities, ed 3. Philadelphia: Saunders, 1995, pp 219-256

35. Martin CT, Pugely AJ, Gao Y, Mendoza-Lattes SA, Ilgenfritz RM, Callaghan JJ, et al: Increasing hospital charges for adolescent idiopathic scoliosis in the United States. Spine (Phila Pa 1976) 39:1676-1682, 2014

36. Menger RP, Guthikonda B, Storey CM, Nanda A, McGirt M, Asher A: Neurosurgery value and quality in the context of the Affordable Care Act: a policy perspective. Neurosurg Focus 39(6):E5, 2015

37. Menger RP, Thakur JD, Jain G, Nanda A: Impact of insurance precertification on neurosurgery practice and health care delivery. J Neurosurg 127:332-337, 2017
38. Merola AA, Haher TR, Brkaric M, Panagopoulos G, Mathur S, Kohani O, et al: A multicenter study of the outcomes of the surgical treatment of adolescent idiopathic scoliosis using the Scoliosis Research Society (SRS) outcome instrument. Spine (Phila Pa 1976) 27:2046-2051, 2002

39. O'Malley KJ, Cook KF, Price MD, Wildes KR, Hurdle JF, Ashton CM: Measuring diagnoses: ICD code accuracy. Health Serv Res 40:1620-1639, 2005

40. Panageas KS, Schrag D, Riedel E, Bach PB, Begg CB: The effect of clustering of outcomes on the association of procedure volume and surgical outcomes. Ann Intern Med 139:658-665, 2003

41. Patil CG, Santarelli J, Lad SP, Ho C, Tian W, Boakye M: Inpatient complications, mortality, and discharge disposition after surgical correction of idiopathic scoliosis: a national perspective. Spine J 8:904-910, 2008

42. Paul JC, Lonner BS, Goz V, Weinreb J, Karia R, Toombs CS, et al: Complication rates are reduced for revision adult spine deformity surgery among high-volume hospitals and surgeons. Spine J 15:1963-1972, 2015

43. Paul JC, Lonner BS, Toombs CS: Greater operative volume is associated with lower complication rates in adolescent spinal deformity surgery. Spine (Phila Pa 1976) 40:162-170, 2015

44. Prabhakaran S, Fonarow GC, Smith EE, Liang L, Xian Y, Neely M, et al: Hospital case volume is associated with mortality in patients hospitalized with subarachnoid hemorrhage. Neurosurgery 75:500-508, 2014

45. Quan H, Sundararajan V, Halfon P, Fong A, Burnand B, Luthi JC, et al: Coding algorithms for defining comorbidities in ICD-9-CM and ICD-10 administrative data. Med Care 43:1130-1139, 2005

46. Rubin DB: Multiple Imputation for Nonresponse in Surveys. New York: Wiley, 1987

47. Schafer JL, Graham JW: Missing data: our view of the state of the art. Psychol Methods 7:147-177, 2002

48. Scoliosis Research Society: Adolescent idiopathic scoliosis. Scoliosis Research Society. (http://www.srs.org/ patients-and-families/conditions-and-treatments/parents/ scoliosis/adolescent-idiopathic-scoliosis) [Accessed August 8, 2017]

49. Sharma K, Kalakoti P, Henry M, Mishra V, Riel-Romero RM, Notarianni C, et al: Revisiting racial disparities in access to surgical management of drug-resistant temporal lobe epilepsy post implementation of Affordable Care Act. Clin Neurol Neurosurg 158:82-89, 2017

50. Shrive FM, Stuart H, Quan H, Ghali WA: Dealing with missing data in a multi-question depression scale: a comparison of imputation methods. BMC Med Res Methodol 6:57, 2006

51. Smith ER, Butler WE, Barker FG II: Craniotomy for resection of pediatric brain tumors in the United States, 1988 to 2000: effects of provider caseloads and progressive centralization and specialization of care. Neurosurgery 54:553-565, 2004

52. Thakur JD, Storey C, Kalakoti P, Ahmed O, Dossani RH, Menger RP, et al: Early intervention in cauda equina syndrome associated with better outcomes: a myth or reality? Insights from the Nationwide Inpatient Sample database 2005-2011. Spine J [epub ahead of print], 2017

53. Theologis AA, Sing DC, Chekeni F, Diab M: National trends in the surgical management of adolescent idiopathic scoliosis: analysis of a national estimate of 60,108 children from the National Inpatient Sample over a 13-year time period in the United States. Spine Deform 5:56-65, 2017

54. Trinh VT, Davies JM, Berger MS: Surgery for primary supratentorial brain tumors in the United States, 2000-2009: effect of provider and hospital caseload on complication rates. J Neurosurg 122:280-296, 2015

55. Vitale MG, Riedel MD, Glotzbecker MP, Matsumoto H, Roye DP, Akbarnia BA, et al: Building consensus: development of 
a Best Practice Guideline (BPG) for surgical site infection (SSI) prevention in high-risk pediatric spine surgery. J Pediatr Orthop 33:471-478, 2013

56. Weinstein SL, Dolan LA, Wright JG, Dobbs MB: Effects of bracing in adolescents with idiopathic scoliosis. N Engl J Med 369:1512-1521, 2013

57. Weiss HR, Goodall D: Rate of complications in scoliosis surgery-a systematic review of the Pub Med literature. Scoliosis 3:9, 2008

58. White H: A heteroskedasticity-consistent covariance matrix estimator and a direct test for heteroskedasticity. Econometrica $48: 817-838,1980$

\section{Disclosures}

The authors report no conflict of interest concerning the materi- als or methods used in this study or the findings specified in this paper.

\section{Author Contributions}

Conception and design: Menger, Kalakoti. Acquisition of data: Menger, Kalakoti. Analysis and interpretation of data: Menger, Kalakoti. Drafting the article: Menger, Kalakoti. Critically revising the article: Menger, Kalakoti, Sin. Reviewed submitted version of manuscript: all authors. Statistical analysis: Kalakoti. Administrative/technical/material support: Sin. Study supervision: Menger, Kalakoti, Nanda, Sin.

\section{Correspondence}

Richard Menger, Department of Neurosurgery, LSU Health Sciences Center-Shreveport, 1501 Kings Highway, PO Box 33932, Shreveport, LA 71130-3932. email: richard.menger@ gmail.com. 